\title{
Map-Based Cloning and Functional Analysis of YE1 in Rice, Which Is Involved in Light-Dependent Chlorophyll Biogenesis and Photoperiodic Flowering Pathway
}

\author{
Youlin Peng ${ }^{1,+}\left(\mathbb{D}\right.$, Ting Zou ${ }^{1, *}++^{(D)}$, Lamei Li ${ }^{1}$, Shiwen Tang ${ }^{1}$, Qiao Li ${ }^{2}$, Jie Zhang ${ }^{1}$, \\ Yongjun Chen ${ }^{1}$, Xuechun Wang ${ }^{1}$, Guotao Yang ${ }^{1}$ and Yungao $\mathrm{Hu}^{1}{ }^{1}$ * \\ 1 Rice Research Institute, Southwest University of Science and Technology, Mianyang 621010, China; \\ youlinp@hotmail.com (Y.P.); xkdllm@126.com (L.L.); shiwentang_th@sina.com (S.T.); \\ zhangjie0930123@163.com (J.Z.); cyj6495453@163.com (Y.C.); xuechunwang@swust.edu.cn (X.W.); \\ yangguotao2377893@163.com (G.Y.) \\ 2 College of Landscape Architectural, Sichuan Agricultural University, Chengdu 611130, China; \\ lqsdswj@126.com \\ * $\quad$ Correspondence: zouting.tb@gmail.com (T.Z.); swust.rri@163.com (Y.H.) \\ + These authors contributed equally to this work.
}

Received: 12 January 2019; Accepted: 7 February 2019; Published: 11 February 2019

\begin{abstract}
Light is one of the most important environmental factors that affect many aspects of plant growth, including chlorophyll (Chl) synthesis and flowering time. Here, we identified a rice mutant, yellow leaf and early flowering (ye1), and characterized the gene YE1 by using a map-based cloning method. YE1 encodes a heme oxygenase, which is localized to the chloroplasts. YE1 is expressed in various green tissues, especially in leaves, with a diurnal-rhythmic expression pattern, and its transcripts is also induced by light during leaf-greening. The mutant displays decreased Chl contents with less and disorderly thylakoid lamellar layers in chloroplasts, which reduced the photosynthesis rate. The early flowering phenotype of ye1 was not photoperiod-sensitive. Furthermore, the expression levels of Chl biosynthetic genes were downregulated in ye1 seedlings during de-etiolation responses to light. We also found that rhythmic expression patterns of genes involved in photoperiodic flowering were altered in the mutant. Based on these results, we infer that YE1 plays an important role in light-dependent $\mathrm{Chl}$ biogenesis as well as photoperiodic flowering pathway in rice.
\end{abstract}

Keywords: rice (Oryza sativa L.); light; chlorophyll biosynthesis; photoperiodic flowering; map-based cloning

\section{Introduction}

The growth of plants is affected by various environmental factors, including light, temperature and gravity. Among them, light has special and important significance for green flowering plants. Light is not only a source of energy for photosynthesis, but also an important signal for plant growth [1]. Light regulates several aspects of plant development-including germination, stem growth, leaf and root development, and phototropism—as well as Chl synthesis and flowering time [2].

$\mathrm{Chl}$ is an essential pigment involved in photosynthesis in chloroplasts [3]. It captures, transforms and redirects light energy [4]. These processes are critical for photosynthetic organisms. In higher plants, Chl contains chlorophyll $a(\mathrm{Chl} a)$ and chlorophyll $b(\mathrm{Chl} b)$. The Chl synthesis process starts from glutamate through a series of processes to produce $\mathrm{Chl} a$, and then catalyzed by chlorophyllide 
$a$ oxygenase (CAO) to form $\mathrm{Chl} b$ [5]. In angiosperms, the synthesis of $\mathrm{Chl}$ is inseparable from the participation of light [6]. In rice, mutants of OsCAO1 gene have pale green leaves; and the expression of OsCAO1 is induced by light [7]. 5-aminolevulinic acid (ALA) is a key precursor in chlorophyll biosynthesis [8]. Illumination increases the ALA accumulation; the expression levels of genes encoding glutamyl-tRNA reductase (GluTR) and glutamate-1-semialdehyde aminotransferase (GSAT) that catalyze ALA synthesis are also rapidly upregulated after illumination [9]. Phytochrome (PHY) mainly perceives red light and far red light [10]. In Arabidopsis, PHYA and PHYB together regulate the expression of $H E M A$, the gene encoding a GluTR for ALA synthesis [11,12]; phytochrome-interacting factor 1 (PIF1) directly or indirectly regulates the expression of POR (encoding a protochlorophyllide oxidoreductase) and $\mathrm{FeCh}$ II (encoding a ferrochelatase), which are key genes in Chl synthesis pathways [13].

Flowering is the conversion of vegetative growth to reproductive growth and is the most important process for determining the reproduction in angiosperms [14]. In addition to the Chl synthesis, light also regulates flowering time of plant through photoperiod [15]. Isolation of genes related to photoperiod response revealed the molecular mechanism about the flowering time in plants. In Arabidopsis, CONSTANS (CO) gene encodes a transcription factor that determines the integration of the circadian clock signal into light signal and regulates the transcript level of FLOWERING LOCUS T $(F T)$, which induces flowering in response to long-day (LD) $[16,17]$. In the normal day/night cycle, the transcription of $C O$ changes rhythmically within a day [18]. The expression of the CYCLING DOF FACTORs (CDFs) and GIGANTEA (GI) in the photoperiod pathway is regulated by the circadian rhythm $[19,20]$. CDFs and GI sense the circadian rhythm of clock genes and transmit signals to CO. CO expression is inhibited by CDF genes and is promoted by GI. In the afternoon, CDF protein is degraded by FLAVIN BINDING, KELCH REPEAT, F-BOX 1 (FKF1), thus the expression of CO will increase [19]. Under short-day (SD) conditions, the expression of $C O$ only reaches a high level at night; under LD conditions, $C O$ transcription can reach high level at dusk and night; this difference in expression of $C O$ between LD and SD conditions ultimately determines the diversification in flowering time of plants [21,22]. Cryptochrome (CRY) and PHY also participate in the regulation of photoperiodic flowering [23]. PHY senses red light and far red light, while CRY perceives blue light and ultraviolet light. They regulate circadian rhythms by playing as a role of day-length and light strength sensors and stabilizing transcriptional products of $C O$ [24].

Heme oxygenase (HO) converts the heme to biliverdin IX (BV), ferrous iron $\left(\mathrm{Fe}^{2+}\right)$, and carbon monoxide (CO) [25]. BV is required for the synthesis of phytochrome-chromophore (PФB) in plants [26]. In Arabidopsis, $\mathrm{HO} 1$ has been shown to be localized to the chloroplast; hy1 mutant is caused by the mutation of $\mathrm{HO} 1$ and may have defects in PФB biosynthesis [27]. In maize, ELONGATED MESOCOTYL 2 (ELM2) is a HO1 homolog; elm2 mutant seedlings have deficient Chl synthesis in de-etiolation responses to red light and far red light [28]. In rice, a homologous genes of HO1 and $\mathrm{OsHO1}$ have been identified from rice nuclear genome. OsHO1 is expressed in green tissues [29], with a higher expression level during the daytime and a lower expression level in the late afternoon and at night [30]. A knockdown mutant of OsHO1 showed yellow-green leaves with defects in Chl biosynthesis [29]. Another allelic mutant with a 1-bp deletion in the first exon of OsHO1 exhibits early flowering and photoperiodic insensitivity $[30,31]$. These findings suggest that $\mathrm{OsHO1}$ may participate in responses of $\mathrm{Chl}$ biogenesis or flowering control to light.

In this study, we performed a map-based cloning of the ye1 locus in rice and revealed that ye1 harbors a single-base substitution in the coding region of OsHO1, which resulted in a premature stop codon in its translational products. Based on expression analysis of $Y E 1$ and related genes and the phenotypic observation of ye1, we proposed that YE1 plays important roles in both two pathways of light-dependent chlorophyll biogenesis and photoperiodic flowering at the same time. 


\section{Results}

\section{1. ye1 Mutant Exhibits Impaired Chloroplast Development and Photosynthesis}

The ye1 mutant was isolated from a rice mutant library (in background of a Japonica cultivar Wuyungeng 21) mutagenized with ethyl methanesulfonate (EMS). At the seedling stage, ye1 showed a yellow leaf phenotype, while the leaves of the wild-type Wuyungeng 21 (WT) appeared pale-green (Figure 1A). Compared with the green leaves of the WT, ye1's leaves were yellow-green at the early tillering stage (Figure 1B). To explore the yellow leaf phenotype of ye1 further, we measured the photosynthetic pigment contents at two different stages. The results showed that, at the seedling stage, ye1 had significant reductions of $\mathrm{Chl} a, \mathrm{Chl} b$, and total Chls, whereas the carotenoids were comparable compared with those in the WT (Figure 1C). At the tillering stage, although the Chl contents of ye1 is increased compared with which at the seedling stage (Figure 1C), they were still significantly lesser than that of the WT (Figure 1C). Besides, the level of carotenoids in ye1 decreased at the tillering stage compared with that of the WT (Figure 1C). These data suggested that leaf-color phenotype of ye1 was caused by the reduced $\mathrm{Chl}$ contents.
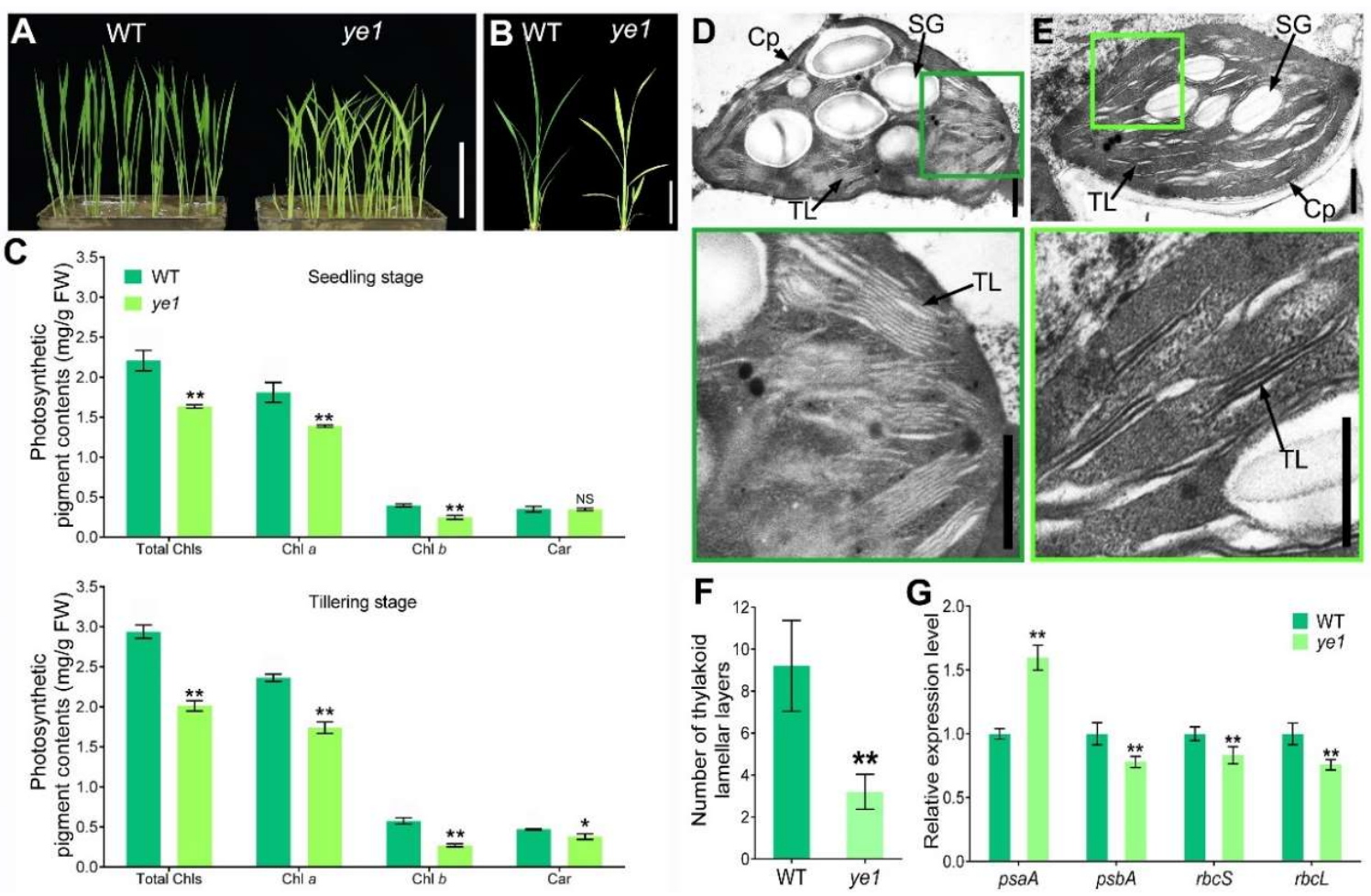

Figure 1. Leaf-color phenotypes of WT and ye1. (A) The appearance of WT and ye1 at the seedling stage. Bar $=10 \mathrm{~cm}$. (B) The appearance of WT and ye1 at the early tillering stage. Bar $=10 \mathrm{~cm}(\mathbf{C})$ Comparisons between the WT and yel in pigment contents at the seedling stage and tillering stage. (D,E) TEM analysis of leaves in the WT (D) and yel (E) seedlings. Cp, chloroplast; SG, starch grain; TL, thylakoid lamellar layer. Bars $=1 \mu \mathrm{m}$. (F) Number of thylakoid lamellar layers in the chloroplasts of WT and ye1 seedlings. (G) Expression levels of genes related to Photosynthesis in WT and yel plant at the heading stage. Each value is given as means \pm standard deviation (SD) or standard errors of mean $(\mathrm{SEM})(n=3)$. NS, no significant change. ${ }^{*}(p<0.05)$ and ${ }^{* *}(p<0.01)$ indicate significant differences between WT and ye1 (Student's t-test).

To investigate the chloroplast development in ye1, transmission electron microscope (TEM) analysis was performed to compare the ultrastructure of chloroplasts in the leaves of WT and ye1 at the seedling stage. Although the mesophyll cells of WT (Figure 1D) and ye1 (Figure 1E) displayed fully developed chloroplasts, the decreased number of thylakoid lamellar layers was observed in 
ye1, and these thylakoid lamellar layers were poorly arranged compared with which of the WT (Figure 1D-F). These results suggested that ye1 had impaired chloroplast development that correlated with its leaf-color and Chl contents. To determine whether photosynthetic apparatus was affected in ye1, we examined the parameters of Chl fluorescent and photosynthetic efficiency between the WT and ye1 under field conditions. As shown in Table 1, significant reductions of the effective quantum yield of PSII (ФPSII), electron transport rate (ETR), and maximum quantum yield of PSII (Fv/Fm) were detected in ye1 compared with the WT. Moreover, ye1 had much lower values in photosynthetic efficiency of net photosynthetic rate (Pn), stomatal conductance (Gs), and transpiration rate (Tr) than those of the WT, while changes in intercellular $\mathrm{CO}_{2}$ concentration (Ci) were not evident (Table 1). The expression levels of photosynthesis-associated genes of the WT and ye1 were also detected using real-time quantitative PCR (qPCR). The results showed that the transcript levels of a gene encoding the subunit of photosystem I ( $p s a A$ ) was significantly upregulated in ye1, whereas genes encoding the core component of Photosystem II ( $p s b A$ ), small subunit of Rubisco $(r b c S)$ and Rubisco large subunit $(r b c L)$ apparently downregulated in ye1 compared with those of the WT (Figure 1G). These findings suggested that photosynthesis was deficient in ye1.

Table 1. Chl fluorescence and photosynthetic parameters of WT and yel mutant.

\begin{tabular}{|c|c|c|c|c|c|c|c|}
\hline Plant & ФPSII & ETR & $\mathrm{F}_{\mathrm{v}} / \mathrm{F}_{\mathrm{m}}$ & $\begin{array}{c}\mathrm{Pn} \\
\left(\mu \mathrm{mol} \cdot \mathrm{CO}_{2} \cdot \mathrm{m}^{-2} \cdot \mathrm{s}^{-1}\right)\end{array}$ & $\begin{array}{c}\mathrm{Gs} \\
\left(\mathrm{mol} \cdot \mathrm{H}_{2} \mathrm{O} \cdot \mathrm{m}^{-2} \cdot \mathrm{s}^{-1}\right)\end{array}$ & $\begin{array}{c}\mathrm{Ci} \\
\left(\mu \mathrm{mol} \cdot \mathrm{CO}_{2} \cdot \mathrm{m}^{-2} \cdot \mathrm{s}^{-1}\right)\end{array}$ & $\begin{array}{c}\mathrm{Tr} \\
\left(\mathrm{mmol} \cdot \mathrm{H}_{2} \mathrm{O} \cdot \mathrm{m}^{-2} \cdot \mathrm{s}^{-1}\right)\end{array}$ \\
\hline WT & $0.74 \pm 0.02$ & $9.43 \pm 0.05$ & $0.84 \pm 0.01$ & $17.57 \pm 0.21$ & $0.90 \pm 0.16$ & $268.0 \pm 6.55$ & $10.62 \pm 0.36$ \\
\hline yel & $0.71 \pm 0.01$ * & $6.93 \pm 0.07^{* *}$ & $0.73 \pm 0.01 * *$ & $5.65 \pm 0.17^{* *}$ & $0.48 \pm 0.09$ ** & $264.0 \pm 13.50^{\mathrm{NS}}$ & $3.40 \pm 0.22 * *$ \\
\hline
\end{tabular}

ФPSII, effective quantum yield of PSII; ETR, electron transport rate; $\mathrm{F}_{\mathrm{v}} / \mathrm{F}_{\mathrm{m}}$, maximum quantum yield of PSII; Pn, net photosynthetic rate; $\mathrm{Gs}$, stomatal conductance; $\mathrm{Ci}$, intercellular $\mathrm{CO}_{2}$ concentration; $\mathrm{Tr}$, transpiration rate. Values are given as means $\pm \mathrm{SD}(n=3)$. NS, no significant change. ${ }^{*}(p<0.05)$ and ${ }^{* *}(p<0.01)$ indicate significant differences between WT and ye1 (Student's $t$-test).

\section{2. ye1 Mutant Displays Early Flowering}

In addition to the yellow leaf, the ye1 mutant was found to have an early flowering phenotype (Figure 2A). Under natural LD (NLD) condition, ye1 showed a 36.4-day earlier flowering than the WT (Figure 2B). Moreover, the number of days to flowering (DTF) of ye 1 also reduced by 14.3 under natural SD (NSD) condition compared with the WT (Figure 2B). Although a significant decrease was found in the DTF of the WT under NSD condition when compared with which under NLD condition, ye1 showed a similar DTF under these two different photoperiodic conditions (Figure 2B). These results indicated that the early flowering phenotype of ye1 was not photoperiod-sensitive.

The other agronomic traits of WT and ye1 were also compared under NLD or NSD condition. In contrast to the WT, the main agronomic traits including plant height, number of tillers per plant, and number of grains per panicle were remarkably reduced in ye1 under NLD or NSD conditions (Figure 2C and Figure S1). However, no significant difference in grain size and weight was found between the WT and ye1 (Figure 2C). 

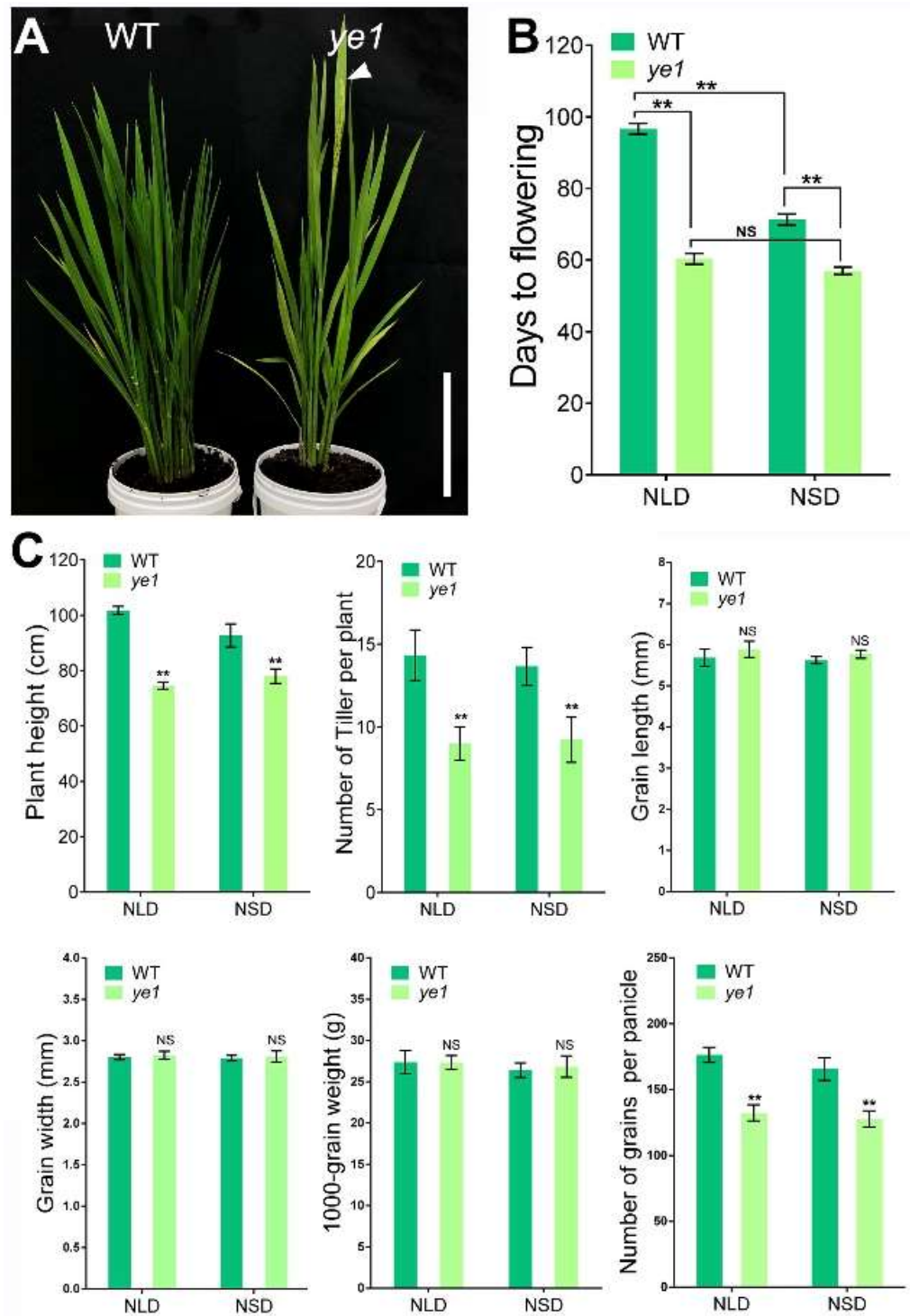

Figure 2. Flowering time phenotypes and other agronomic traits of WT and ye1. (A) Phenotype of WT and ye1 under NLDs, when ye1 was heading. The arrow indicates the flower. Bar $=25 \mathrm{~cm}$. (B) Days to flowering of WT and ye1 under NLDs and NSDs (mean \pm SD, $n=3$ ). NS, no significant change. Significant differences were shown as ${ }^{* *}(p<0.01)$ by Student's $t$-test $(\mathbf{C})$ Other agronomic traits (including plant height, tillering number, grain length, grain width, 1000-grain weight, and number of grains per panicle) of WT and ye1 under NLDs and NSDs. Each value is given as means $\pm \operatorname{SD}(n=3)$. NS, no significant change. ${ }^{* *}(p<0.01)$ indicate significant differences between WT and ye1 (Student's $t$-test).

\subsection{Map-Based Cloning of YE1 and Complementation Analysis}

For genetic analysis of the ye1 mutant, cross between ye1 and indica variety Shuhui 498 was generated. All $F_{1}$ plants displayed normal green leaves and heading dates. Among the 4163 individuals in $F_{2}$ population, 1062 plants showed the phenotype of yellow leaves and early flowering, whereas the other plants of $\mathrm{F}_{2}$ population grew normally. These data indicated that the separate ratio of $\mathrm{F}_{2}$ plants was about 3:1 $\left(3101: 1062, \chi^{2}=0.5785<\chi^{2} 0.05=3.84\right)$, suggesting that the abnormal leaf-color and flowering time phenotype of ye1 was controlled by a single recessive nuclear locus. We then performed map-based cloning to identify the YE1 locus. The YE1 locus was initially mapped to a region on the long arm of chromosome 6 between SSR markers RM20223 and RM5371 (Figure 3A). To fine map the YE1 locus, we developed several polymorphic InDel (ID) markers between ye1 and Shuhui 498. 
By using these ID markers to analyze 822 individuals with yellow leaves and early flowering, the YE1 locus was delimited to an $84.7 \mathrm{~kb}$ interval between ID4 and ID6 (Figure 3B). Within the fine mapping region, a total of 11 open reading frames (ORFs) were predicted (http:/ / rice.plantbiology.msu.edu, Figure $3 \mathrm{C}$ ). We then sequenced the genome DNA of these ORFs. Among them, only one single nucleotide polymorphism (SNP) mutation located in the first exon of LOC_Os06g40080 was found, compared with which of the WT (Figure 3D). This mutation yields a premature stop codon (Figure 3D) and was predicted to produce truncated polypeptides that resulted in a deletion of the whole HO domain (PFAM Accession Number: PF01126.13, Figure S2). Further linkage analysis was carried out by sequencing the mutation site of individuals from the F2 population generated from the cross between ye1 and WT. The results showed that all of the plants with yellow leaves and early flowering had the same homozygous mutation at this locus, whereas the normal plants were homozygous wild-type or heterozygous genotype, indicating this mutation was co-segregated with the leaf-color and flowering time phenotype of ye1 (Figure 3E and Table S1).

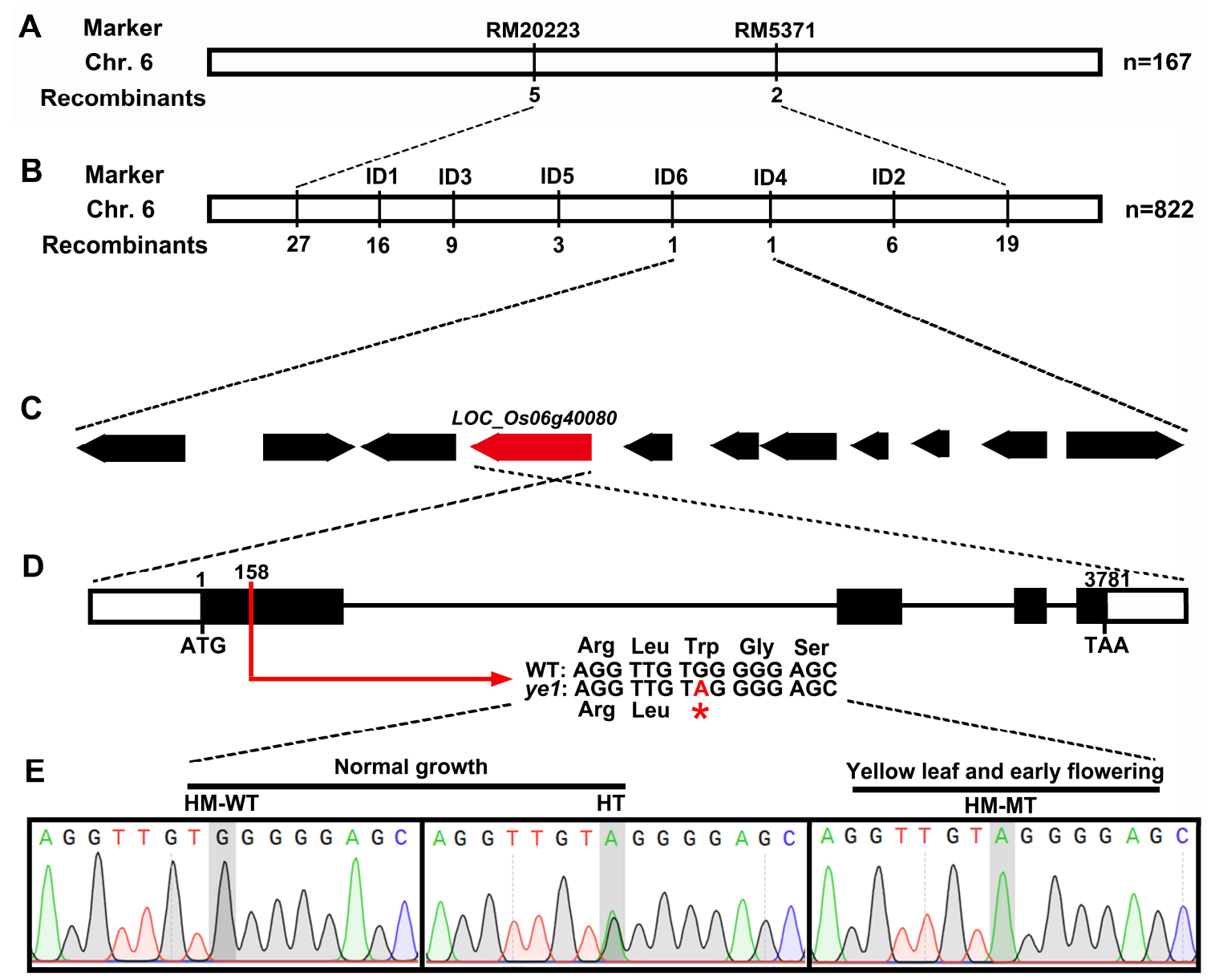

Figure 3. Map-based cloning and identification of the YE1 gene. (A) The YE1 locus was mapped to the interval between molecular markers RM20223 and RM5371 on chromosome 6. (B) The YE1 locus was further delimited to a $\sim 85 \mathrm{~kb}$ genomic region between markers ID4 and ID6. (C) The candidate region contained eleven ORFs. (D) The gene structure of candidate LOC_06g40080. The red arrow indicates the ye1 mutation at 158 nucleotide position in LOC_06g40080, which changes Ter at position 53 to a stop codon. The asterisk indicates the stop codon. (E) The identification of the YE1 gene in the ye1/WT $\mathrm{F}_{2}$ population by sequencing.

To confirm whether LOC_Os06g40080 corresponds to YE1, we produced transgenic rice plants by introducing a construct consisting of a $2.5-\mathrm{kb}$ upstream promoter and the full-length cDNA sequence of the wild-type LOC_Os06g40080 gene (Figure 4A) to the ye1 mutant via Agrobacterium-mediated 
transformation. Phenotypic observations showed that all the positive transgenic lines had normal green leaves (Figure 4B); and their photosynthetic pigment contents were also indistinguishable from that of the WT (Figure 4C). Besides, the number of DTF of these positive transgenic lines were similar to that of the WT under NLD or NSD condition (Figure 4D,E). Taken together, the results suggested that LOC_Os06g 40080 is the YE1 gene, and that ye1 is a loss-of-function mutant of YE1 gene.
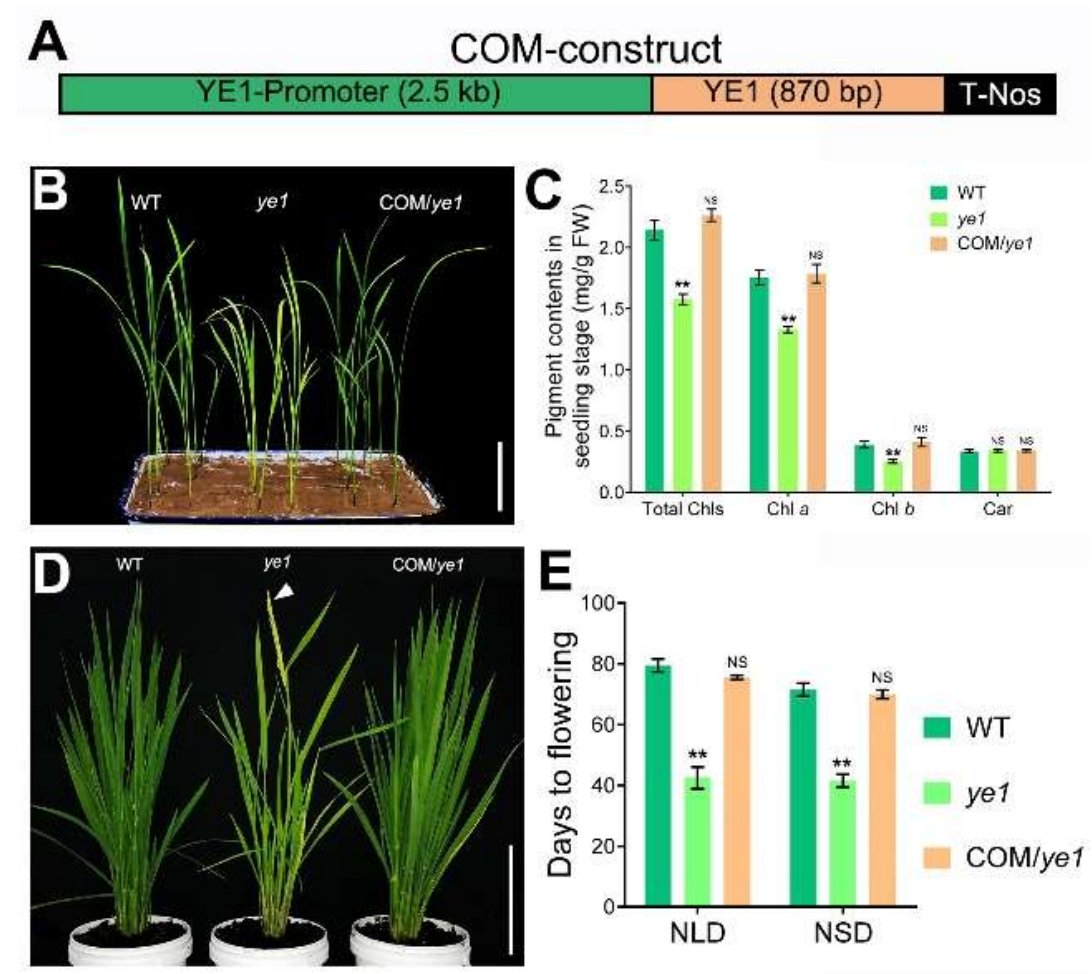

Figure 4. Complementation of ye1 mutant. (A) The construct for complementary analysis of YE1 gene. (B) Leaf color phenotypes of WT, ye1 and complementary plants (COM/ye1). Bar $=5 \mathrm{~cm}$. (C) Comparisons of pigment contents of WT, ye1 and complementary plants. (D) Flowering time phenotypes of WT, ye1 and complementary plants under NLDs, when ye1 was heading. The arrow indicates the flower. Bar $=25 \mathrm{~cm}$. (E) Days to flowering of WT, ye1 and complementary plants under NLDs and NSDs. Each value is given as means \pm SD $(n=3)$. NS, no significant change. ${ }^{*}(p<0.05)$ and ** $(p<0.01)$ indicate significant differences compared with WT (Student's $t$-test).

\subsection{YE1 Protein Is Conserved in Land Plants}

YE1 (LOC_Os06g40080) was annotated to encode HO1 in rice (OsHO1, http: / / rice.plantbiology. msu.edu). This protein was reported previously as the key regulator of photoperiod sensitivity (named SE5) or chlorophyll biosynthesis (named YGL2) [29-31]. In this study, we refer to OsHO1/SE5/YGL2 as 'YE1'. By using YE1 protein sequence as a search query for BLASTP in the Phytozome database (http:/ / www.phytozome.net), 25 closest related proteins of YE1 from other land plant species were retrieved (Table S2). Multiple peptides alignment results of these proteins indicated that their HO domain were highly conserved among different species, whereas a high sequence diversity was found in their N-terminal region (Figure S3). A neighbor-joining phylogenetic tree of these proteins were constructed based on the results of protein sequences alignment. The YE1-realtives were clustered into three clades-dicots, mosses and monocots, the proteins in which had $\sim 57 \%, \sim 50 \%$, and $\sim 73 \%$ identity to the YE1 protein, respectively (Figure 5). These results suggested that YE1 is conserved in land plants, and may share similar functions with its homologs in other species. 


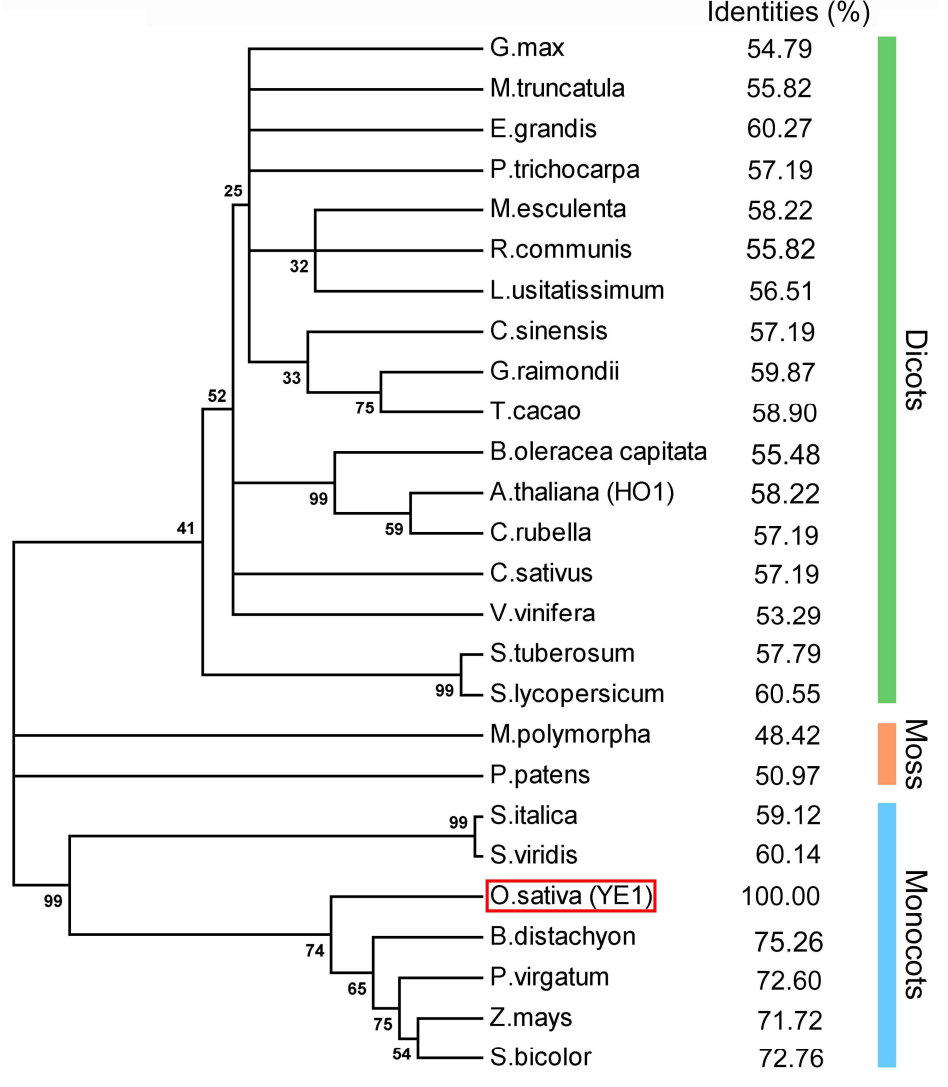

$\begin{array}{llllllllllll}0.16 & 0.14 & 0.12 & 0.10 & 0.08 & 0.06 & 0.04 & 0.02 & 0.00\end{array}$

Figure 5. Protein phylogenic analysis among YE1 and YE1-related proteins. A neighbor-joining phylogenic analysis was performed using MEGA 5.0, based on the alignment result in Supplementary Figure S3. The YE1-related proteins are clearly clustered into three clades. Green, orange and blue bars represent the three different clades, which indicate the homologous proteins of YE1 from the species in dicots, moss and monocots, respectively. The YE1 protein is highlighted by the red box. The numbers at the nodes indicate the bootstrap value. The percentage numbers represent the identities of corresponding proteins to YE1.

\subsection{Expression Pattern and Subcellular Location of YE1}

The expression pattern of YE1 gene was detected using qPCR. The results showed that YE1 exhibited a strong expression in leaf, with a relatively weaker mRNA level in root, stem, sheath, and panicle (Figure 6A). Besides, the maximal transcription level of YE1 was observed within the leaf at the seedling stage, but its expression extremely reduced at tillering, jointing, and booting stage, and was relatively weak at heading stage, suggesting that expression of $Y E 1$ was also influenced by leaf developmental stage. To test whether YE1 expression is regulated by light, we examined the temporal expression patterns of $Y E 1$ during leaf greening of the WT etiolated seedlings. The results showed a sharply increased expression of $Y E 1$ after exposure of 10-day-old etiolated WT seedlings to light (Figure 6B), suggesting that transcription of $Y E 1$ is induced by light during leaf greening. Due to the mutation of $Y E 1$ caused a photoperiod-insensitive phenotype of ye1, we therefore tested the behavior of YE1 in the WT plants under different photoperiodic conditions. Our qPCR results showed that the transcripts of $Y E 1$ started to accumulate from $8 \mathrm{~h}$ after dawn, reaching a peak at $10 \mathrm{~h}$ after dusk under both LDs and SDs (Figure 6C), suggesting that the expression of YE1 is diurnal-rhythmic.

To determine the subcellular localization of YE1 protein, we fused green fluorescent protein (GFP) to the C-terminal of YE1 under the control of the cauliflower mosaic virus 35S promoter ( $p 35 s:: Y E 1-G F P)$, and transiently expressed this plasmid in the epidermal cells of tobacco leaves. 
Transient expression results showed that, as the control, the $p 35 s:: G F P$ were expressed throughout the cells (Figure 6D), whereas the strong fluorescent signals of $p 35 s:: Y E 1-G F P$ were observed in the chloroplast-like structures of the cells (Figure S4). To confirm this subcellular localization pattern, we observed the auto-fluorescence of chloroplasts. Via merging the micrographs from each channel, we found that the detected green fluorescent signals of $p 35$ s::YE1-GFP completely overlapped with chloroplasts' auto-fluorescence (Figure 6E). This result suggested that YE1 protein is targeted to the chloroplasts.

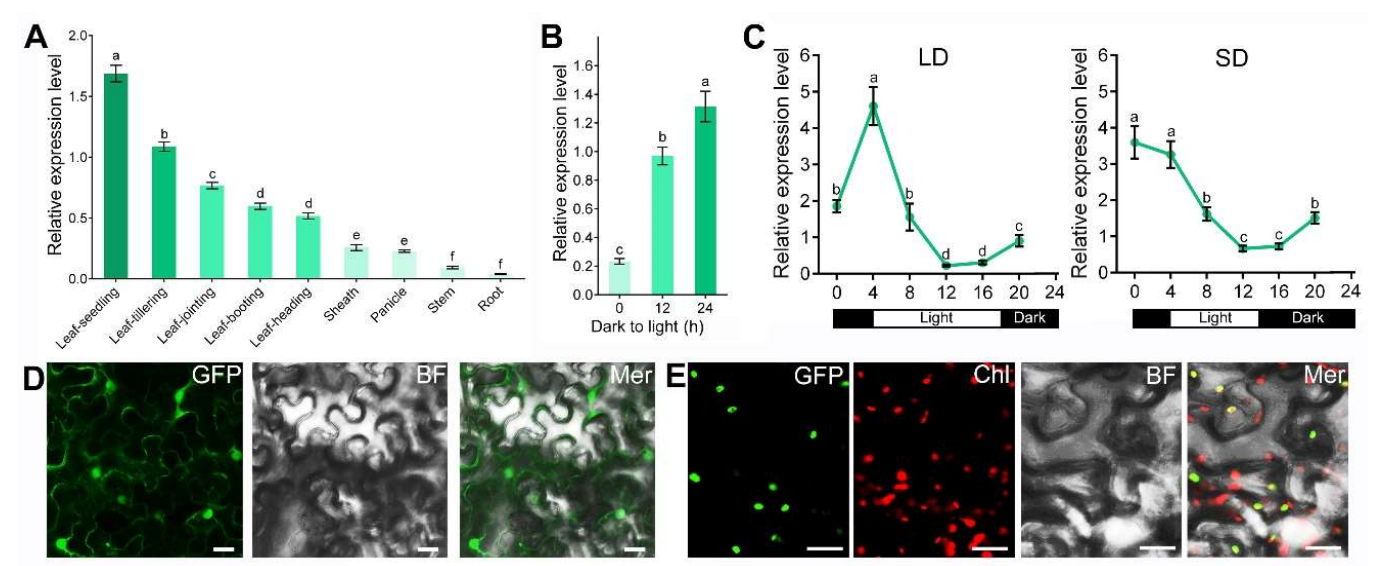

Figure 6. The expression pattern and subcellular localization of YE1. (A) YE1 expression levels in different tissues. (B) YE1 expression levels during light-induced greening of WT etiolated seedlings. After growing in darkness for 10 days, etiolated WT seedlings were illuminated for 12 or $24 \mathrm{~h}$. (C) Rhythmic expression of YE1 under LDs and SDs. (D) Subcellular localization of GFP protein (control). (E) Subcellular localization of YE1-GFP fusion protein. BF, bright field; Chl, chloroplasts' auto-fluorescence; Mer, merge of each channel. Bars $=10 \mu \mathrm{m}$. Each value is given as means $\pm \mathrm{SEM}$ $(n=3)$. Different letters indicate the statistical differences at $p<0.05$ by Duncan's test.

\subsection{YE1 Is Involved in Light-Dependent Chl Synthesis}

The synthesis of Chl molecules is strongly induced by light exposure in angiosperms [6]. To explore the contribution of $Y E 1$ to light-dependent $\mathrm{Chl}$ synthesis, we compared the Chl contents of the WT and ye1 etiolated seedlings during light-induced leaf greening. Unlike the WT etiolated seedlings that quickly turn green after being exposed to light, ye1 seedlings remained pale yellow after $24 \mathrm{~h}$ of illumination (Figure 7A). The accumulation of both $\mathrm{Chl} a$ and $\mathrm{Chl} b$ in ye1 plants lagged far behind ones in the WT plants throughout the whole light exposure period (Figure 7B). To understand the molecular basis of YE1 involvement in light-dependent $\mathrm{Chl}$ synthesis, we also examined the temporal expression profiles of several $\mathrm{Chl}$ synthesis-associated genes during light-induced leaf greening of the WT and ye1 etiolated seedlings. For example, DVR encodes a divinyl reductase, which catalyze the conversion of divinyl Chl $a$ to monovinyl Chl $a$ [32,33]; OsCAO1 encodes a Chl $a$ oxygenase, which catalyze the synthesis of $\mathrm{Chl} b$ from $\mathrm{Chl} a[7,34]$; OsCHLH and OsCHLD participate in the synthesis of $\mathrm{Chl}$ precursors by producing two different subunits of magnesium-chelatase [35-40]; OsPORA is a NADPH: protochlorophyllide oxidoreductase A in rice, and catalyzes the photoreduction of chlorophyllide from protochlorophyllide in Chl synthesis [41]; YGL1 encodes a Chl synthase that catalyzes the esterification of chlorophyllide to form $\mathrm{Chl} a$ [42]. The qPCR results showed that (Figure 7C), the transcription levels of DVR, OsCAO1, OsCHLD, OsCHLH, and YGL1 were upregulated during light-induced greening in WT seedlings, suggesting that these genes are required for the light-dependent $\mathrm{Chl}$ synthesis during de-etiolation. Consistent with the previous report [41], OsPORA expression drastically decreased upon illumination. However, compared with that in the WT plants, the expression of DVR, OsCHLH, OsPORA, and YGL1 were reduced in ye1 plants. Only OsCAO1 and $O S C H L D$ expression levels in ye1 were comparable with that of the WT. These observations indicated that the transcript levels of genes related to $\mathrm{Chl}$ synthesis were altered in ye1 during leaf 
greening and suggested that $Y E 1$ likely plays an important role in the light-dependent synthesis of Chl during de-etiolation.

\subsection{Diurnal Expression Patterns of Flowering Genes Are Altered in ye1}

The photoperiodic pathway is one of the most important pathways for plants flowering control. Several genes have been reported to be involved in rice photoperiodic flowering pathway. For example, Days to heading $(D T H) 7$ is a major genetic locus that controls the delayed flowering of rice under LDs, and its expression is regulated by photoperiod [43]. DTH8 encodes a HAP3 subunit of HAP complex, and delays flowering by inhibiting the expression of 'florigen' genes under LDs [44]. Early flowering 7 (EF7) gene is a rice ortholog of Arabidopsis ELF3, which promotes flowering under both LDs and SDs [45]. Early heading date 2 (EHD2) is a key factor in the flowering transformation of rice and encodes a transcription factor with a zinc finger motif; it is an ortholog of INDETERMINATE1 (ID1), which also promotes flowering in maize [46,47]. Heading date 1 (HD1) is a member of the rice CO family, which promotes flowering under SDs but inhibits flowering under LDs; HD1 is located downstream of EHD2, and is an important integration point of signaling in the conserved pathway of flowering regulation [47-49]. Heading date 16 (Hd16) encodes a casein kinase I that inhibits flowering under LDs [50]. The expression of OsGI is controlled by photoperiod, which is similar to its homolog in Arabidopsis; but under LDs, OsGI inhibits flowering, which is different from Arabidopsis GI [51-53]. We therefore compared the expression levels of these genes between the WT and ye1 mutant under different photoperiodic conditions. qPCR results indicated that the peak phases of DTH7 expression slightly decreased in ye1 mutants under both LDs (Figure 8A) and SDs (Figure 8B) compared with which of the WT. Similarly, the expression levels of HD16 and OsGI in ye1 mutant were lower than that of the WT under LDs (Figure 8A). However, mRNA levels of EHD2 were not significantly affected in ye1 mutant (Figure 8A,B). Transcript levels of DTH8 were largely reduced in ye1 mutants under both LDs (Figure 8A) and SDs (Figure 8B). Strikingly, under LDs, but not SDs, EF7 mRNA levels were markedly upregulated in ye1 mutants after dawn (Figure $8 \mathrm{~A}$ ). These results suggested that the mutation in $Y E 1$ affected the expression profiles of the genes known to be related to photoperiodic flowering.

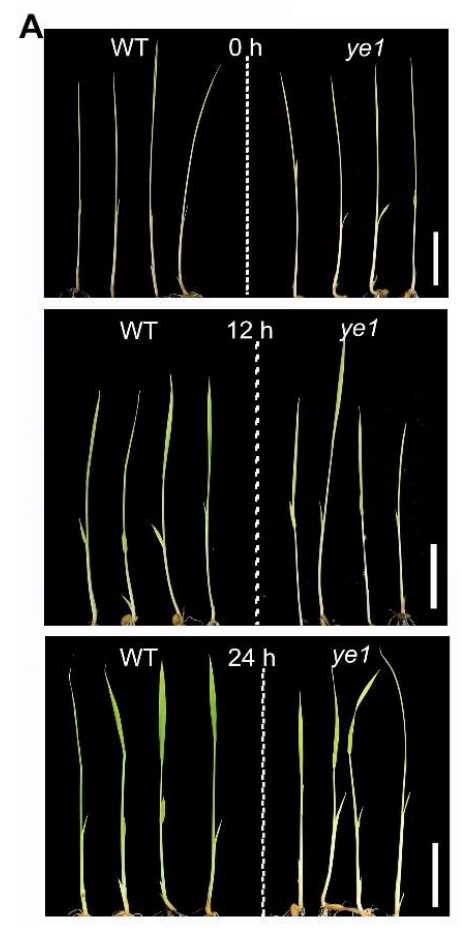

Figure 7. Cont. 
B
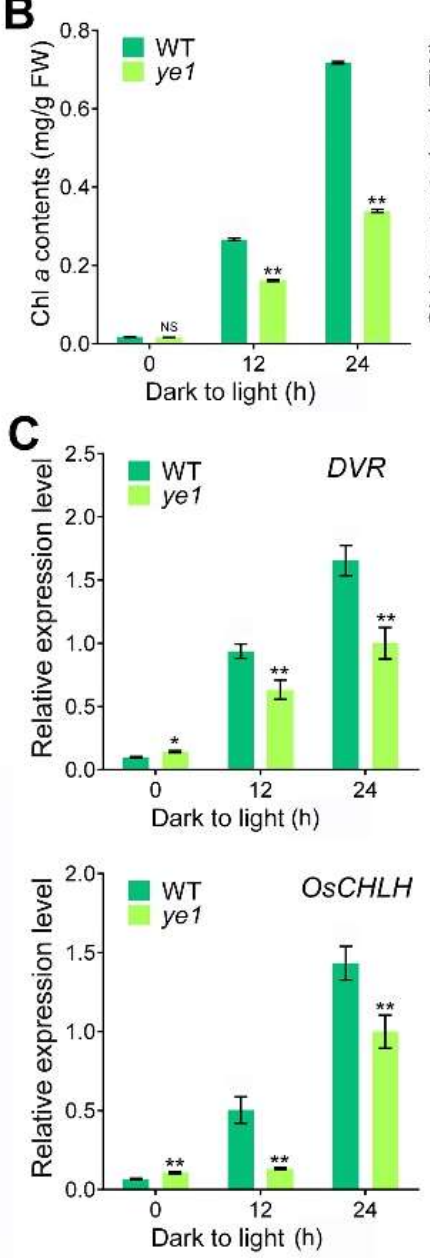
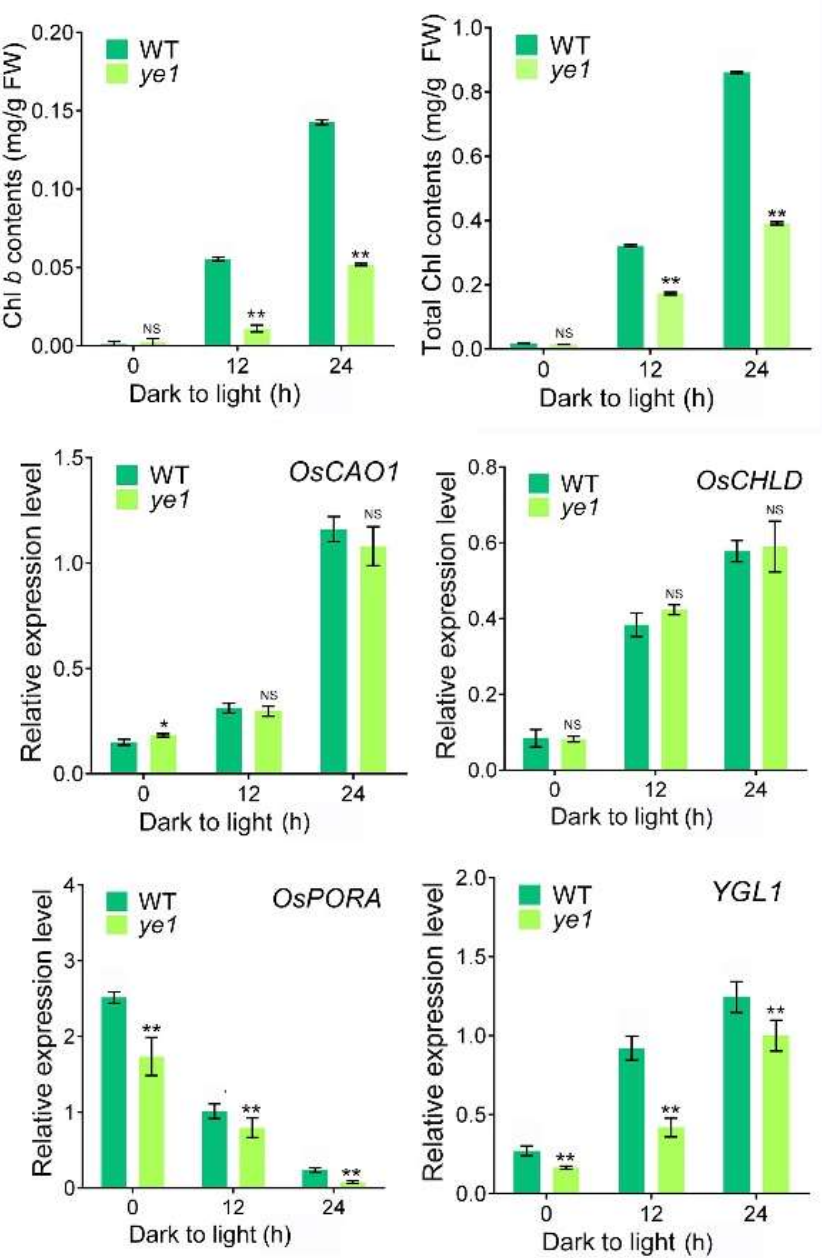

Figure 7. Expression levels of Chl synthesis-associated genes in WT and ye1. (A) Comparisons of greening speed in WT and ye1 etiolated seedlings that were exposed to light for $12 \mathrm{or} 24 \mathrm{~h}$. Bar $=5 \mathrm{~cm}$. (B) Comparisons of $\mathrm{Chl}$ contents in the WT and ye1 etiolated seedlings during light-induced greening. (C) Comparisons of changes in expression levels of Chl synthesis-associated genes in WT and ye1 etiolated seedlings during light-induced greening. Each value is given as means $\pm \operatorname{SD}$ or $\operatorname{SEM}(n=3)$. NS, no significant change. ${ }^{*}(p<0.05)$ and ${ }^{* *}(p<0.01)$ indicate significant differences compared with WT (Student's t-test).

\section{Discussion}

Rice is one of the most important food crops in the world, and is also a model of monocots. To date, a range of genes in rice have been reported to function in Chl biogenesis, such as DVR, FGL, LYL1, OsCAO1, OsCHLD, OsCHLH, OsPORA, OsPORB, YGL1, YGL2, and YLC1 [7,29,32,36-38,40,41,54-57]. Leaf $\mathrm{Chl}$ contents affect grain formation by affecting photosynthetic efficiency in rice [58]. Meanwhile, photoperiodic flowering has been extensively studied in rice, and many corresponding genes have been identified during past years, such as DTH7, DTH8, EF7, EHD1, HD1, HD3A, OsGI, OsMADS50, OsMADS51, OsMADS56, RID1, RFT1, and SE5 [30,43-46,48,51-53,59-63]. In addition, flowering time is usually associated with vegetative growth as well as yield-related traits [64]. In this work, we isolate a rice mutant ye1. The ye1 mutant has yellow leaves with a significant reduction of Chl content and impaired chloroplast development and photosynthesis (Figure 1), and shows early flowering phenotype (Figure 2A,B). Besides, in ye1 mutant, plant height, tiller numbers, and grain numbers per panicle are also drastically decreased (Figure 2C), suggesting a low yield. Further investigations found that $Y E 1$ is responsible for the phenotypes of ye1, suggesting that mutation in $Y E 1$ results in low yields, and YE1 may have potential application of improving yields in rice breeding. 

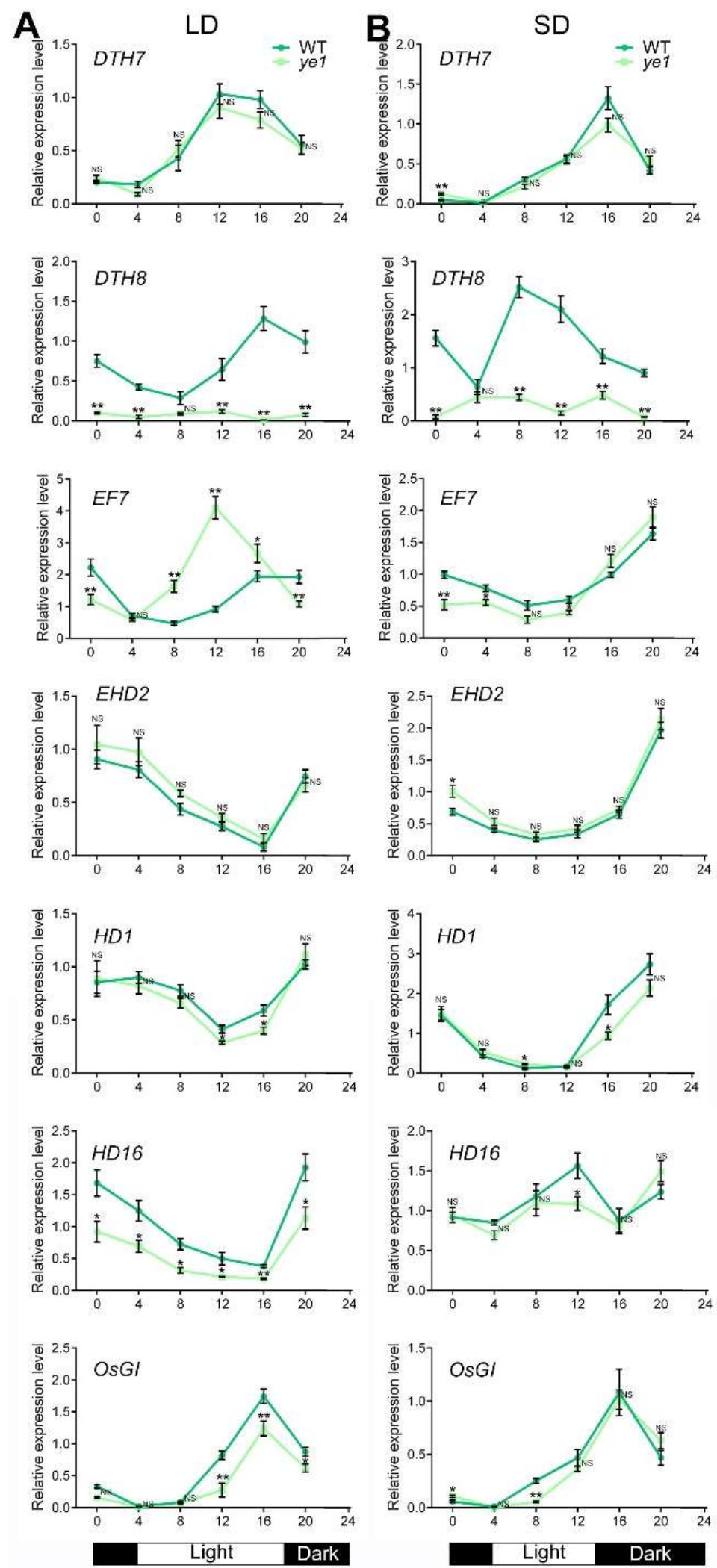

Figure 8. Rhythmic expression patterns of photoperiodic flowering-associated genes in WT and ye1. (A) Rhythmic expression patterns of DTH7, DTH8, EF7, EHD2, HD1, HD16, and OsGI under LDs. (B) Rhythmic expression patterns of DTH7, DTH8, EF7, EHD2, HD1, HD16, and OsGI under SDs. Each value is given as means $\pm \operatorname{SEM}(n=3)$. NS, no significant change. ${ }^{*}(p<0.05)$ and ${ }^{* *}(p<0.01)$ indicate significant differences compared with WT (Student's $t$-test). 
Light response plays an important role in plant growth, development, and metabolism. Light induces Chl synthesis in the de-etiolation process of plant seedlings [2]. The results of this work show that the expression of YE1 gene peaks in WT seedling leaves (Figure 6A) and is induced by light during leaf greening (Figure 6B). Moreover, Chl synthesis in ye1 etiolated seedlings lags far behind that of WT (Figure 7A and B), suggesting that $Y E 1$ is involved in light-dependent $\mathrm{Chl}$ synthesis. DVR, OsCAO1, OsCHLH, and YGL1 proteins were reported to be critical for Chl synthesis, and are encoded in the rice nuclear genome [7,32,38,42]. Our qPCR results indicated that transcript levels of these nuclear genes increased in WT plants after illumination (Figure 7C), which is consistent with previous reports [7], and suggest these genes may function in light-induced synthesis of Chl. However, DVR, OsCHLH, and YGL1 expression were downregulated in the ye1 plants (Figure 7C). This may cause the resulting lower Chl contents in ye1 (Figure 7B). Though YE1 protein is located to the chloroplasts (Figure 6E), signals from the plastids to the nucleus is critical to regulate nuclear gene expression [65]. Based on these results, we speculate that YE1 may play an essential role in light-dependent $\mathrm{Chl}$ synthesis of chloroplasts and propose that YE1 may affect nuclear gene expression through plastid-to-nucleus retrograde signaling.

In addition, light also affects the flowering time of plants through different photoperiods [2]. In this study, we show that $Y E 1$ has different diurnal rhythmic expression patterns when under different day-length conditions (Figure 6C), suggesting that YE1 may respond to the changes of photoperiods. Rice is a SD plant $[51,66]$. Similarly, in WT plants, DTF under NLDs is longer than which under NSDs (Figure 2B). However, flowering times of ye1 mutant under between NLDs and NSDs are comparable (Figure 2B), suggesting that ye1 mutant has less or no photoperiodic-sensitivity, and YE1 may play roles in photoperiod response. This photoperiodic-insensitive phenotype of ye1 is different from that of hy1 mutant in Arabidopsis [67], whereas YE1 is an ortholog of Arabidopsis HO1 (Figure 5 and Figure S3), reflecting various roles of $\mathrm{HO}$ between monocots and dicots. Besides, the flowering time of our ye1 mutant was significantly earlier than that of WT under NLDs (Figure 2A,B). Coincidently, expression analyses showed that transcript level of $E F 7$, which promotes flowering both under LDs and under SDs [45], is significantly upregulated in ye1 mutant under LDs but not obviously changed under SDs compared with which of WT (Figure 8). Expression of DTH7, HD16, and OsGI, which play roles in delaying flowering time under LDs [43,50,52], is suppressed in mutant under LDs (Figure 8A). Apart from that, $\mathrm{DTH} 8$ is another major genetic factor that delays flowering by inhibiting the expression of 'florigen' genes under LDs [44]; its transcription decreased markedly in ye1 mutant under both LDs and SDs (Figure 8). Collectively, these data suggest that YE1 may participate in photoperiodic flowering control by affecting the diurnal expression profiles of genes involved in the photoperiod pathway.

In higher plants, phytochrome is a family of photoreceptors that receive and respond to red/far-red light [68], and also plays a major role in response to photoperiod [21,69]. РФВ participates in the regulation of many essential developmental processes (including seedling de-etiolation and flowering) through forming phytochrome by combining with apoprotein $[70,71]$. BV, as a product derived from HO-catalyzed oxidative cleavage of heme, is the precursor of РФВ [25,72]. In Arabidopsis, the mutation of HO1 causes the hy1 mutant to do not respond to red and far-red light [73], and be deficient in BV and subsequent РФВ synthesis [27]. Another HO-deficient mutant of pea ( $p c d 1)$ was also shown to be unable to convert heme to BV and have severely impaired ability in РФВ biosynthesis [74]. These findings suggest that $\mathrm{HO}$ functions in $Р \Phi В$ biosynthesis, and is required for normal photomorphogenesis. Apart from affecting the plant's response to light through producing BV, the substrate of the HO-catalyzed reaction may also be involved in the synthesis of $\mathrm{Chl}$. The synthesis of ALA, which is catalyzed by GluTR and GSAT, is a key step in Chl biogenesis [75]. Thus, the enzymatic activity of GluTR is critical for Chl biosynthesis [76]. It was reported that application of exogenous heme reduced the enzymatic activity of barley GIuTR1 by 50\% [77]. Both mutations in the yg-2 and au mutants of tomato led to a yellow-green phenotype, and the normal heme turnover in the plastids of these mutants was blocked [78]. Arabidopsis ulf3 is an allelic mutant of hy1. In ulf3 mutant, the decrease in $\mathrm{HO}$ activity caused the accumulation of heme, while the accumulation of heme inhibited the activity 
of GluTR [79]. These data indicate that HO may participate in the biosynthesis of Chl by affecting the heme accumulation, which has feedback inhibition of the enzymatic activity of GluTR. Our results of peptides alignment indicated that the whole HO domain of YE1 in our ye1 mutant is deleted (Figure S2), and YE1 is conserved in land plants (Figure 5). Combining the above findings with these results, we raise a possibility that ye1 is likely to be a HO-deficient mutant, and may also have probable deficiencies of $\mathrm{P} \Phi \mathrm{B}$ biosynthesis and GluTR activity, which may result in the mutant phenotypes of photoperiodic-insensitive flowering and impaired $\mathrm{Chl}$ biogenesis.

The se 5 mutants display a serve defect in photoperiodic response and a very early heading date [31]. The $y g l 2$ is an allelic mutant of se5, and shows yellow-green leaves and a reduction of Chl contents [29], suggesting that SE5/YGL2, which encodes the OsHO1, may be related to Chl biosynthesis or photoperiodic flowering control. However, it is still unclear whether OsHO1 can participate in these two pathways at the same time. In the present study, our ye1 mutant exhibits defective chloroplast development and photoperiodic response simultaneously. Results of map-based cloning revealed that YE1 is another allele of $S E 5 / Y G L 2$ but has different mutation site. The se5 mutant was isolated from japonica rice cultivar Norin 8, and a single base deletion of A406 was found in its first exon, which caused the frame-shift of SE5 [31]. The ygl2 mutant was derived from indica rice variety Gang $46 \mathrm{~B}$, and has a 7-kb insertion in the first exon, resulting in a decreased expression of YGL2. Our ye1 mutant was characterized from japonica rice cultivar Wuyungeng 21. Sequencing results indicated a single base substitution from G158 to A158 at the first exon of YE1 in ye1 mutant. This point mutation changed a tryptophan (Trp) to a stop codon at the 53rd amino acid (Figure 3D), which resulted in the absence of the whole HO domain (Figure S2). Interestingly, se5 and ye1 exhibited the similar photoperiodic-insensitive flowering phenotype, whereas ygl2 and ye 1 appeared similar defects in Chl biogenesis that has not been reported in se5. These findings suggest that YE1 may play roles in both Chl biogenesis and photoperiodic response, and we also infer that different mutation sites in various backgrounds may result in different manifestations of gene functions.

\section{Materials and Methods}

\subsection{Plant Materials and Growth Condition}

The mutant line ye1 was derived from the japonica rice cultivar Wuyungeng 21 through EMS mutagenesis. EMS treatment and mutant screening were performed as described previously [80]. For phenotypic analysis, rice plants were grown and maintained regularly under either NLDs in Mianyang, Sichuan, China (average day-length >13.6) or NSDs in Lingshui, Hainan, China (average day-length $<11.7$ ). For light-dependent leaf greening experiments, rice seedlings were grown in continuous darkness for 10 days and subsequently exposed to light for 12 or $24 \mathrm{~h}$. For diurnal rhythmic expression analysis, rice seedlings were cultivated in a growth chamber under either LDs (14 h of light $/ 10 \mathrm{~h}$ of dark) or SDs (10 h of light/14 h of dark) for four weeks; leaves were then collected every $4 \mathrm{~h}$, for $24 \mathrm{~h}$.

\subsection{Morphological, Physiological, and Cellular Analysis}

Determinations of pigment contents and photosynthetic and Chl fluorescence parameters for leaves were performed as described previously [81]. To observe the chloroplasts of seedling leaves, a TEM (Hitachi, H-600, Tokyo, Japan) was employed, and the samples were prepared as described previously [82]. The grain length, width, and 1000-grain weight were measured using an automatic seed-size analyzing system (Wanshen, SC-G, Shenzhen, China). Other agronomic traits were investigated using conventional methods at maturing stage. The data were analyzed using the software program GraphPad Prism 7.0 (https:/ / www.graphpad.com/, San Diego, CA, USA) for mean values and SD or SEM. Statistical significance was assessed by conducting Student's $t$-test or Duncan's test. 


\subsection{Map-Based Cloning of YE1}

The ye1 mutant was crossed with an indica variety Shuhui 498, and the resulting F1 was further selfed to generate the $\mathrm{F} 2$ population. For primary mapping, $167 \mathrm{~F}_{2}$ mutant plants were used to map the YE1 locus to the region between markers RM20223 and RM5371 on chromosome 6. The YE1 locus was further fine mapped to an 84.7-kb genomic interval between the markers ID6 and ID4 by using $822 \mathrm{~F}_{2}$ mutant plants. The mutation of YE1 gene in the mutant was confirmed by PCR products sequencing with the primer set YE1-SEQ. All the primers used in this study are listed in Table S3.

\subsection{Vector Construction and Transgenic Analysis}

To verify the YE1 function, we generated a complementary construct by amplifying the full-length $Y E 1 \mathrm{cDNA}$ and its native promoter (a 2.5-kb DNA fragment upstream of the start codon ATG of YE1) from WT with primer sets YE1-COM and PYE1-COM, respectively. These two fragments were thereafter inserted into the plant binary vector PCAMBIA1300 in front of NOS terminator to generate the COM-construct ( $p Y E 1:: Y E 1)$. The COM-construct was introduced into the Agrobacterium tumefaciens strain EHA105, and was then transferred into the mutant in accordance with a method published previously [83]. Eight positive transgenic lines were obtained.

\subsection{Expression Analysis}

Total RNA of various rice tissues was extracted using the E.Z.N.A. ${ }^{\circledR}$ Plant RNA Kit (Omega Bio-tek, Norcross, GA, USA) and reverse transcribed using the HiScript ${ }^{\circledR}$ Q Select RT SuperMix kit (Vazyme, Nanjing, China) in accordance with the manufacturer's instructions. qPCR was performed by using the AceQ qPCR SYBR Green Master Mix (Vazyme, Nanjing, China) with the corresponding primer sets on a Real-Time PCR System (Bio-Rad, CFX96, Hercules, CA, USA). OsACTIN1 was used as the normalized reference gene. The relative levels of gene expression were calculated as described previously [84].

\subsection{Subcellular Localization of YE1}

To determine the subcellular localization of YE1, the full-length cDNA of YE1 was amplified with primer set YE1-GFP, and was then cloned into the expression vector pBI121-GFP, resulting in a C-terminal fusion with GFP. This plasmid was expressed in tobacco (Nicotiana benthamiana) leaf epidermal cells by Agrobacterium-mediated infiltration following the method described previously [85]. The fluorescent signals of GFP was visualized using a confocal laser scanning microscope (Nikon, A1, Tokyo, Japan) after $48 \mathrm{~h}$ of infiltration.

\subsection{Phylogenetic Analysis of YE1}

The 25 YE1-related protein sequences from other land plant species were retrieved from Phytozome database (www.phytozome.net, accessed on 06-09-2018) by using BLASTP tool with the full-length amino acids sequence of YE1 as a query and default parameters. A total of 26 protein sequences (including YE1) were aligned using ClustalW [86]. The phylogenetic tree was generated using the software program MEGA 5.0 with the neighbor-joint method [87]. Tree topology was analyzed by using full removal mode with 1000 bootstrap replications.

\section{Conclusions}

In summary, we isolated a mutant ye1 from EMS-induced japonica rice mutant library. Morphological, physiological, and cellular analysis indicate that this mutant not only had yellow leaves with impaired Chl biogenesis and photosynthesis, but also exhibited an early flowering phenotype without photoperiodic-sensitivity. Map-based cloning analysis revealed that the casual gene YE1 of this mutant was a new allele of $S E 5 / Y G L 2$, which encodes a chloroplast-located HO in rice. Furthermore, expression analysis uncovered that transcripts of $Y E 1$ was induced by light, and had a diurnal-rhythmic 
pattern. Taken together, these results suggest that YE1 may participates in light-dependent Chl synthesis during de-etiolation and be required for the photoperiodic flowering control simultaneously in rice.

Supplementary Materials: Supplementary materials can be found at http:/ /www.mdpi.com/1422-0067/20/3/ $758 /$ s1.

Author Contributions: T.Z. and Y.H. conceived the project and supervised this study. Y.P. and T.Z. designed the experiment, analyzed the data and wrote the manuscript; Y.P., T.Z., L.L., S.T., Q.L., J.Z., Y.C., X.W. and G.Y. performed the experiments. All the authors read and approved the final manuscript.

Funding: This research was funded by the Southwest University of Science and Technology PhD Research Fund (grant number 18zx7126), National Key R\&D Program of China (grant number 2017YFD0100201), the Educational Commission of Sichuan Province, China (grant number 18ZA0507), State Key Laboratory of Rice Biology, China (grant number 160202), and College Students' Innovation and Entrepreneurship Training Program of Sichuan Province (grant number 18xcy074).

Acknowledgments: The authors are grateful to Guo Yang for his assistance in TEM analysis.

Conflicts of Interest: The authors declare no conflict of interest.

\section{References}

1. Fankhauser, C.; Chory, J. Light Control of Plant Development. Annu. Rev. Cell Dev. Biol. 1997, 13, $203-229$. [CrossRef] [PubMed]

2. Kami, C.; Lorrain, S.; Hornitschek, P.; Fankhauser, C. Chapter Two-Light-Regulated Plant Growth and Development. In Current Topics in Developmental Biology; Timmermans, M.C.P., Ed.; Academic Press: Amsterdam, Netherland, 2010; Volume 91, pp. 29-66.

3. Fromme, P.; Melkozernov, A.; Jordan, P.; Krauss, N. Structure and function of photosystem I: Interaction with its soluble electron carriers and external antenna systems. FEBS Lett. 2003, 555, 40-44. [CrossRef]

4. Stenbaek, A.; Jensen, P.E. Redox regulation of chlorophyll biosynthesis. Phytochemistry 2010, 71, 853-859. [CrossRef] [PubMed]

5. Von Wettstein, D. Chlorophyll Biosynthesis. In Plant Molecular Biology 2; Herrmann, R.G., Larkins, B.A., Eds.; Springer: Boston, MA, USA, 1991; pp. 449-459.

6. Suzuki, J.Y.; Bauer, C.E. A prokaryotic origin for light-dependent chlorophyll biosynthesis of plants. Proc. Natl. Acad. Sci. USA 1995, 92, 3749-3753. [CrossRef] [PubMed]

7. Yang, Y.; Xu, J.; Huang, L.; Leng, Y.; Dai, L.; Rao, Y.; Chen, L.; Wang, Y.; Tu, Z.; Hu, J.; et al. PGL, encoding chlorophyllide a oxygenase 1 , impacts leaf senescence and indirectly affects grain yield and quality in rice. J. Exp. Bot. 2016, 67, 1297-1310. [CrossRef] [PubMed]

8. Papenbrock, J.; Grimm, B. Regulatory network of tetrapyrrole biosynthesis-studies of intracellular signalling involved in metabolic and developmental control of plastids. Planta 2001, 213, 667-681. [CrossRef]

9. Liu, D.; Kong, D.D.; Fu, X.K.; Ali, B.; Xu, L.; Zhou, W.J. Influence of exogenous 5-aminolevulinic acid on chlorophyll synthesis and related gene expression in oilseed rape de-etiolated cotyledons under water-deficit stress. Photosynthetica 2016, 54, 468-474. [CrossRef]

10. Franklin, K.A.; Quail, P.H. Phytochrome functions in Arabidopsis development. J. Exp. Bot. 2010, 61, 11-24. [CrossRef]

11. Casal, J.J. Phytochromes, Cryptochromes, Phototropin: Photoreceptor Interactions in Plants. Photochem. Photobiol. 2000, 71, 1-11. [CrossRef]

12. McCormac, A.C.; Terry, M.J. Light-signalling pathways leading to the co-ordinated expression of HEMA1 and Lhcb during chloroplast development in Arabidopsis thaliana. Plant J. 2002, 32, 549-559. [CrossRef]

13. Moon, J.; Zhu, L.; Shen, H.; Huq, E. PIF1 directly and indirectly regulates chlorophyll biosynthesis to optimize the greening process in Arabidopsis. Proc. Natl. Acad. Sci. USA 2008, 105, 9433-9438. [CrossRef] [PubMed]

14. Jung, C.; Müller, A.E. Flowering time control and applications in plant breeding. Trends Plant Sci. 2009, 14, 563-573. [CrossRef] [PubMed]

15. Yu, X.; Lin, C. Light Regulation of Flowering Time in Arabidopsis. In Light Sensing in Plants; Wada, M., Shimazaki, K.-I., Iino, M., Eds.; Springer: Tokyo, Japan, 2005; pp. 325-332. 
16. Suárez-López, P.; Wheatley, K.; Robson, F.; Onouchi, H.; Valverde, F.; Coupland, G. CONSTANS mediates between the circadian clock and the control of flowering in Arabidopsis. Nature 2001, 410, 1116-1120. [CrossRef] [PubMed]

17. Kardailsky, I.; Shukla, V.K.; Ahn, J.H.; Dagenais, N.; Christensen, S.K.; Nguyen, J.T.; Chory, J.; Harrison, M.J.; Weigel, D. Activation Tagging of the Floral Inducer FT. Science 1999, 286, 1962-1965. [CrossRef] [PubMed]

18. An, H.; Roussot, C.; Suárez-López, P.; Corbesier, L.; Vincent, C.; Piñeiro, M.; Hepworth, S.; Mouradov, A.; Justin, S.; Turnbull, C.; et al. CONSTANS acts in the phloem to regulate a systemic signal that induces photoperiodic flowering of Arabidopsis. Development 2004, 131, 3615-3626. [CrossRef] [PubMed]

19. Imaizumi, T.; Schultz, T.F.; Harmon, F.G.; Ho, L.A.; Kay, S.A. FKF1 F-Box Protein Mediates Cyclic Degradation of a Repressor of CONSTANS in Arabidopsis. Science 2005, 309, 293-297. [CrossRef] [PubMed]

20. Sawa, M.; Nusinow, D.A.; Kay, S.A.; Imaizumi, T. FKF1 and GIGANTEA complex formation is required for day-length measurement in Arabidopsis. Science 2007, 318, 261-265. [CrossRef] [PubMed]

21. Hayama, R.; Coupland, G. The molecular basis of diversity in the photoperiodic flowering responses of Arabidopsis and rice. Plant Physiol. 2004, 135, 677-684. [CrossRef]

22. Shim, J.S.; Kubota, A.; Imaizumi, T. Circadian Clock and Photoperiodic Flowering in Arabidopsis: CONSTANS Is a Hub for Signal Integration. Plant Physiol. 2017, 173, 5-15. [CrossRef]

23. Mockler, T.; Yang, H.; Yu, X.; Parikh, D.; Cheng, Y.-c.; Dolan, S.; Lin, C. Regulation of photoperiodic flowering by Arabidopsis photoreceptors. Proc. Natl. Acad. Sci. USA 2003, 100, 2140-2145. [CrossRef]

24. Valverde, F.; Mouradov, A.; Soppe, W.; Ravenscroft, D.; Samach, A.; Coupland, G. Photoreceptor Regulation of CONSTANS Protein in Photoperiodic Flowering. Science 2004, 303, 1003-1006. [CrossRef]

25. Shekhawat, G.S.; Verma, K. Heme oxygenase (HO): An overlooked enzyme of plant metabolism and defence. J. Exp. Bot. 2010, 61, 2255-2270. [CrossRef] [PubMed]

26. Terry, M.J.; Linley, P.J.; Kohchi, T. Making light of it: The role of plant heme oxygenases in phytochrome chromophore synthesis. Biochem. Soc. Transact. 2002, 30, 604-609. [CrossRef]

27. Muramoto, T.; Kohchi, T.; Yokota, A.; Hwang, I.; Goodman, H.M. The Arabidopsis photomorphogenic mutant hy1 is deficient in phytochrome chromophore biosynthesis as a result of a mutation in a plastid heme oxygenase. Plant Cell 1999, 11, 335-348. [CrossRef] [PubMed]

28. Shi, D.; Zheng, X.; Li, L.; Lin, W.; Xie, W.; Yang, J.; Chen, S.; Jin, W. Chlorophyll Deficiency in the Maize elongated mesocotyl2 Mutant Is Caused by a Defective Heme Oxygenase and Delaying Grana Stacking. PLoS ONE 2013, 8, e80107. [CrossRef] [PubMed]

29. Chen, H.; Cheng, Z.; Ma, X.; Wu, H.; Liu, Y.; Zhou, K.; Chen, Y.; Ma, W.; Bi, J.; Zhang, X.; et al. A knockdown mutation of YELLOW-GREEN LEAF2 blocks chlorophyll biosynthesis in rice. Plant Cell Rep. 2013, 32, 1855-1867. [CrossRef] [PubMed]

30. Andrés, F.; Galbraith, D.W.; Talón, M.; Domingo, C. Analysis of PHOTOPERIOD SENSITIVITY5 Sheds Light on the Role of Phytochromes in Photoperiodic Flowering in Rice. Plant Physiol. 2009, 151, 681-690. [CrossRef] [PubMed]

31. Izawa, T.; Oikawa, T.; Tokutomi, S.; Okuno, K.; Shimamoto, K. Phytochromes confer the photoperiodic control of flowering in rice (a short-day plant). Plant J. 2000, 22, 391-399. [CrossRef] [PubMed]

32. Wang, P.; Gao, J.; Wan, C.; Zhang, F.; Xu, Z.; Huang, X.; Sun, X.; Deng, X. Divinyl Chlorophyll(ide) a Can Be Converted to Monovinyl Chlorophyll(ide) a by a Divinyl Reductase in Rice. Plant Physiol. 2010, 153, 994-1003. [CrossRef] [PubMed]

33. Wang, P.; Wan, C.; Xu, Z.; Wang, P.; Wang, W.; Sun, C.; Ma, X.; Xiao, Y.; Zhu, J.; Gao, X.; et al. One Divinyl Reductase Reduces the 8-Vinyl Groups in Various Intermediates of Chlorophyll Biosynthesis in a Given Higher Plant Species, But the Isozyme Differs between Species. Plant Physiol. 2013, 161, 521-534. [CrossRef] [PubMed]

34. Lee, S.; Kim, J.-H.; Yoo, E.S.; Lee, C.-H.; Hirochika, H.; An, G. Differential regulation of chlorophyll a oxygenase genes in rice. Plant Mol. Biol. 2005, 57, 805-818. [CrossRef] [PubMed]

35. Tian, X.; Ling, Y.; Fang, L.; Du, P.; Sang, X.; Zhao, F.; Li, Y.; Xie, R.; He, G. Gene cloning and functional analysis of yellow green leaf3 (ygl3) gene during the whole-plant growth stage in rice. Genes Genom. 2013, 35, 87-93. [CrossRef]

36. Zhang, H.; Li, J.; Yoo, J.-H.; Yoo, S.-C.; Cho, S.-H.; Koh, H.-J.; Seo, H.S.; Paek, N.-C. Rice Chlorina-1 and Chlorina-9 encode ChlD and ChlI subunits of Mg-chelatase, a key enzyme for chlorophyll synthesis and chloroplast development. Plant Mol. Biol. 2006, 62, 325-337. [CrossRef] [PubMed] 
37. Deng, X.-J.; Zhang, H.-Q.; Wang, Y.; He, F.; Liu, J.-L.; Xiao, X.; Shu, Z.-F.; Li, W.; Wang, G.-H.; Wang, G.-L. Mapped Clone and Functional Analysis of Leaf-Color Gene Ygl7 in a Rice Hybrid (Oryza sativa L. ssp. indica). PLoS ONE 2014, 9, e99564. [CrossRef] [PubMed]

38. Goh, C.-H.; Satoh, K.; Kikuchi, S.; Kim, S.-C.; Ko, S.-M.; Kang, H.-G.; Jeon, J.-S.; Kim, C.S.; Park, Y.-I. Mitochondrial activity in illuminated leaves of chlorophyll-deficient mutant rice (OsCHLH) seedlings. Plant Biotechnol. Rep. 2010, 4, 281-291. [CrossRef]

39. Goh, C.H.; Oh, S.; An, G.; Moon, Y.H.; Lee, C.H. Activation of mitochondrial respiration in chlorophyll-deficient rice mutant seedlings. J. Plant Biol. 2007, 50, 430-439. [CrossRef]

40. Ruan, B.; Gao, Z.; Zhao, J.; Zhang, B.; Zhang, A.; Hong, K.; Yang, S.; Jiang, H.; Liu, C.; Chen, G.; et al. The rice YGL gene encoding an $\mathrm{Mg} 2+-$ chelatase ChlD subunit is affected by temperature for chlorophyll biosynthesis. J. Plant Biol. 2017, 60, 314-321. [CrossRef]

41. Sakuraba, Y.; Rahman, M.L.; Cho, S.-H.; Kim, Y.-S.; Koh, H.-J.; Yoo, S.-C.; Paek, N.-C. The rice faded green leaf locus encodes protochlorophyllide oxidoreductase B and is essential for chlorophyll synthesis under high light conditions. Plant J. 2013, 74, 122-133. [CrossRef]

42. Wu, Z.; Zhang, X.; He, B.; Diao, L.; Sheng, S.; Wang, J.; Guo, X.; Su, N.; Wang, L.; Jiang, L.; et al. A Chlorophyll-Deficient Rice Mutant with Impaired Chlorophyllide Esterification in Chlorophyll Biosynthesis. Plant Physiol. 2007, 145, 29-40. [CrossRef]

43. Gao, H.; Jin, M.; Zheng, X.-M.; Chen, J.; Yuan, D.; Xin, Y.; Wang, M.; Huang, D.; Zhang, Z.; Zhou, K.; et al. Days to heading 7 , a major quantitative locus determining photoperiod sensitivity and regional adaptation in rice. Proc. Natl. Acad. Sci. USA 2014, 111, 16337-16342. [CrossRef]

44. Wei, X.; Xu, J.; Guo, H.; Jiang, L.; Chen, S.; Yu, C.; Zhou, Z.; Hu, P.; Zhai, H.; Wan, J. DTH8 Suppresses Flowering in Rice, Influencing Plant Height and Yield Potential Simultaneously. Plant Physiol. 2010, 153, 1747-1758. [CrossRef] [PubMed]

45. Saito, H.; Ogiso-Tanaka, E.; Okumoto, Y.; Yoshitake, Y.; Izumi, H.; Yokoo, T.; Matsubara, K.; Hori, K.; Yano, M.; Inoue, H.; et al. Ef7 Encodes an ELF3-like Protein and Promotes Rice Flowering by Negatively Regulating the Floral Repressor Gene Ghd7 under Both Short- and Long-Day Conditions. Plant Cell Physiol. 2012, 53, 717-728. [CrossRef] [PubMed]

46. Wu, C.; You, C.; Li, C.; Long, T.; Chen, G.; Byrne, M.E.; Zhang, Q. RID1, encoding a Cys2/His2-type zinc finger transcription factor, acts as a master switch from vegetative to floral development in rice. Proc. Natl. Acad. Sci. USA 2008, 105, 12915-12920. [CrossRef] [PubMed]

47. Matsubara, K.; Yamanouchi, U.; Wang, Z.-X.; Minobe, Y.; Izawa, T.; Yano, M. Ehd, a Rice Ortholog of the Maize INDETERMINATE Gene, Promotes Flowering by Upregulating Ehd1. Plant Physiol. 2008, 148, 1425-1435. [CrossRef]

48. Takahashi, Y.; Teshima, K.M.; Yokoi, S.; Innan, H.; Shimamoto, K. Variations in Hd1 proteins, Hd3a promoters, and Ehd1expression levels contribute to diversity of flowering time in cultivated rice. Proc. Natl. Acad. Sci. USA 2009, 106, 4555. [CrossRef] [PubMed]

49. Yano, M.; Katayose, Y.; Ashikari, M.; Yamanouchi, U.; Monna, L.; Fuse, T.; Baba, T.; Yamamoto, K.; Umehara, Y.; Nagamura, Y.; et al. Hd1, a major photoperiod sensitivity quantitative trait locus in rice, is closely related to the Arabidopsis flowering time gene CONSTANS. Plant Cell 2000, 12, 2473-2484. [CrossRef] [PubMed]

50. Hori, K.; Ogiso-Tanaka, E.; Matsubara, K.; Yamanouchi, U.; Ebana, K.; Yano, M. Hd16, a gene for casein kinase $\mathrm{I}$, is involved in the control of rice flowering time by modulating the day-length response. Plant $\mathrm{J}$. 2013, 76, 36-46. [CrossRef] [PubMed]

51. Hayama, R.; Yokoi, S.; Tamaki, S.; Yano, M.; Shimamoto, K. Adaptation of photoperiodic control pathways produces short-day flowering in rice. Nature 2003, 422, 719. [CrossRef] [PubMed]

52. Itoh, H.; Nonoue, Y.; Yano, M.; Izawa, T. A pair of floral regulators sets critical day length for Hd3a florigen expression in rice. Nat. Genet. 2010, 42, 635. [CrossRef]

53. Izawa, T.; Mihara, M.; Suzuki, Y.; Gupta, M.; Itoh, H.; Nagano, A.J.; Motoyama, R.; Sawada, Y.; Yano, M.; Hirai, M.Y.; et al. Os-GIGANTEA Confers Robust Diurnal Rhythms on the Global Transcriptome of Rice in the Field. Plant Cell 2011, 23, 1741-1755. [CrossRef]

54. Zhou, Y.; Gong, Z.; Yang, Z.; Yuan, Y.; Zhu, J.; Wang, M.; Yuan, F.; Wu, S.; Wang, Z.; Yi, C.; et al. Mutation of the Light-Induced Yellow Leaf 1 Gene, Which Encodes a Geranylgeranyl Reductase, Affects Chlorophyll Biosynthesis and Light Sensitivity in Rice. PLoS ONE 2013, 8, e75299. [CrossRef] [PubMed] 
55. Zhou, K.; Ren, Y.; Lv, J.; Wang, Y.; Liu, F.; Zhou, F.; Zhao, S.; Chen, S.; Peng, C.; Zhang, X.; et al. Young Leaf Chlorosis 1 , a chloroplast-localized gene required for chlorophyll and lutein accumulation during early leaf development in rice. Planta 2013, 237, 279-292. [CrossRef] [PubMed]

56. Sakuraba, Y.; Kim, E.-Y.; Han, S.-H.; Piao, W.; An, G.; Todaka, D.; Yamaguchi-Shinozaki, K.; Paek, N.-C. Rice Phytochrome-Interacting Factor-Like1 (OsPIL1) is involved in the promotion of chlorophyll biosynthesis through feed-forward regulatory loops. J. Exp. Bot. 2017, 68, 4103-4114. [CrossRef] [PubMed]

57. Kwon, C.-T.; Kim, S.-H.; Song, G.; Kim, D.; Paek, N.-C. Two NADPH: Protochlorophyllide Oxidoreductase (POR) Isoforms Play Distinct Roles in Environmental Adaptation in Rice. Rice 2017, 10, 1. [CrossRef] [PubMed]

58. Yang, Y.; Xu, J.; Rao, Y.; Zeng, Y.; Liu, H.; Zheng, T.; Zhang, G.; Hu, J.; Guo, L.; Qian, Q.; et al. Cloning and functional analysis of pale-green leaf (PGL10) in rice (Oryza sativa L.). Plant Growth Regul. 2016, 78, 69-77. [CrossRef]

59. RYU, C.-H.; LEE, S.; CHO, L.-H.; KIM, S.L.; LEE, Y.-S.; CHOI, S.C.; JEONG, H.J.; YI, J.; PARK, S.J.; HAN, C.-D.; et al. OsMADS50 and OsMADS56 function antagonistically in regulating long day (LD)-dependent flowering in rice. Plant Cell Environ. 2009, 32, 1412-1427. [CrossRef] [PubMed]

60. Doi, K.; Izawa, T.; Fuse, T.; Yamanouchi, U.; Kubo, T.; Shimatani, Z.; Yano, M.; Yoshimura, A. Ehd1, a B-type response regulator in rice, confers short-day promotion of flowering and controls FT-like gene expression independently of Hd1. Genes Dev. 2004, 18, 926-936. [CrossRef] [PubMed]

61. Kim, S.L.; Lee, S.; Kim, H.J.; Nam, H.G.; An, G. OsMADS51 Is a Short-Day Flowering Promoter That Functions Upstream of Ehd1, OsMADS14, and Hd3a. Plant Physiol. 2007, 145, 1484-1494. [CrossRef]

62. Komiya, R.; Ikegami, A.; Tamaki, S.; Yokoi, S.; Shimamoto, K. Hd3a and RFT1 are essential for flowering in rice. Development 2008, 135, 767-774. [CrossRef]

63. Kojima, S.; Takahashi, Y.; Kobayashi, Y.; Monna, L.; Sasaki, T.; Araki, T.; Yano, M. Hd3a, a Rice Ortholog of the Arabidopsis FT Gene, Promotes Transition to Flowering Downstream of Hd1 under Short-Day Conditions. Plant Cell Physiol. 2002, 43, 1096-1105. [CrossRef]

64. Liu, H.; Li, Q.; Xing, Y. Genes Contributing to Domestication of Rice Seed Traits and Its Global Expansion. Genes 2018, 9. [CrossRef] [PubMed]

65. Kakizaki, T.; Matsumura, H.; Nakayama, K.; Che, F.-S.; Terauchi, R.; Inaba, T. Coordination of plastid protein import and nuclear gene expression by plastid-to-nucleus retrograde signaling. Plant Physiol. 2009, 151, 1339-1353. [CrossRef] [PubMed]

66. Shimamoto, K.; Yokoi, S. The Photoperiodic Control of Flowering in Rice, a Short-Day Plant. In Light Sensing in Plants; Wada, M., Shimazaki, K.-I., Iino, M., Eds.; Springer: Tokyo, Japan, 2005; pp. 339-346.

67. Goto, N.; Kumagai, T.; Koornneef, M. Flowering responses to light-breaks in photomorphogenic mutants of Arabidopsis thaliana, a long-day plant. Physiol. Plantar. 1991, 83, 209-215. [CrossRef]

68. Rockwell, N.C.; Su, Y.-S.; Lagarias, J.C. Phytochrome structure and signaling mechanisms. Annu. Rev. Plant Biol. 2006, 57, 837-858. [CrossRef] [PubMed]

69. Yanovsky, M.J.; Kay, S.A. Living by the calendar: How plants know when to flower. Nat. Rev. Mol. Cell Biol. 2003, 4, 265-275. [CrossRef] [PubMed]

70. Takano, M.; Inagaki, N.; Xie, X.; Yuzurihara, N.; Hihara, F.; Ishizuka, T.; Yano, M.; Nishimura, M.; Miyao, A.; Hirochika, H.; et al. Distinct and cooperative functions of phytochromes A, B, and C in the control of deetiolation and flowering in rice. Plant Cell 2005, 17, 3311-3325. [CrossRef] [PubMed]

71. Bae, G.; Choi, G. Decoding of Light Signals by Plant Phytochromes and Their Interacting Proteins. Annu. Rev. Plant Biol. 2008, 59, 281-311. [CrossRef]

72. Elich, T.D.; McDonagh, A.F.; Palma, L.A.; Lagarias, J.C. Phytochrome chromophore biosynthesis. Treatment of tetrapyrrole-deficient Avena explants with natural and non-natural bilatrienes leads to formation of spectrally active holoproteins. J. Biol. Chem. 1989, 264, 183-189.

73. Chory, J.; Peto, C.A.; Ashbaugh, M.; Saganich, R.; Pratt, L.; Ausubel, F. Different Roles for Phytochrome in Etiolated and Green Plants Deduced from Characterization of Arabidopsis thaliana Mutants. Plant Cell 1989, 1,867-880. [CrossRef]

74. Weller, J.L.; Terry, M.J.; Rameau, C.; Reid, J.B.; Kendrick, R.E. The Phytochrome-Deficient pcd1 Mutant of Pea Is Unable to Convert Heme to Biliverdin IX[alpha]. The Plant cell 1996, 8, 55-67. [CrossRef]

75. Cornah, J.E.; Terry, M.J.; Smith, A.G. Green or red: What stops the traffic in the tetrapyrrole pathway? Trends Plant Sci. 2003, 8, 224-230. [CrossRef] 
76. Kumar, A.M.; Söll, D. Antisense HEMA1 RNA expression inhibits heme and chlorophyll biosynthesis in arabidopsis. Plant Physiol. 2000, 122, 49-56. [CrossRef] [PubMed]

77. Pontoppidan, B.; Kannangara, C.G. Purification and partial characterisation of barley glutamyl-tRNAGlu reductase, the enzyme that directs glutamate to chlorophyll biosynthesis. Eur. J. Biochem. 1994, 225, 529-537. [CrossRef] [PubMed]

78. Terry, M.J.; Kendrick, R.E. Feedback inhibition of chlorophyll synthesis in the phytochrome chromophore-deficient aurea and yellow-green-2 mutants of tomato. Plant Physiol. 1999, 119, 143-152. [CrossRef] [PubMed]

79. Goslings, D.; Meskauskiene, R.; Kim, C.; Lee, K.P.; Nater, M.; Apel, K. Concurrent interactions of heme and FLU with Glu tRNA reductase (HEMA1), the target of metabolic feedback inhibition of tetrapyrrole biosynthesis, in dark- and light-grown Arabidopsis plants. Plant J. 2004, 40, 957-967. [CrossRef]

80. Abe, A.; Kosugi, S.; Yoshida, K.; Natsume, S.; Takagi, H.; Kanzaki, H.; Matsumura, H.; Yoshida, K.; Mitsuoka, C.; Tamiru, M. Genome sequencing reveals agronomically important loci in rice using MutMap. Nat. Biotechnol. 2012, 30, 174. [CrossRef] [PubMed]

81. Akhter, D.; Qin, R.; Nath, U.; Alamin, M.; Jin, X.; Shi, C. The Brown Midrib Leaf (bml) Mutation in Rice (Oryza sativa L.) Causes Premature Leaf Senescence and the Induction of Defense Responses. Genes 2018, 9, 203. [CrossRef] [PubMed]

82. Zou, T.; Xiao, Q.; Li, W.; Luo, T.; Yuan, G.; He, Z.; Liu, M.; Li, Q.; Xu, P.; Zhu, J.; et al. OsLAP6/OsPKS1, an orthologue of Arabidopsis PKSA/LAP6, is critical for proper pollen exine formation. Rice 2017, 10, 53. [CrossRef]

83. Hiei, Y.; Ohta, S.; Komari, T.; Kumashiro, T. Efficient transformation of rice (Oryza sativa L.) mediated by Agrobacterium and sequence analysis of the boundaries of the T-DNA. Plant J. 1994, 6, 271-282. [CrossRef]

84. Dong, H.; Fei, G.-L.; Wu, C.-Y.; Wu, F.-Q.; Sun, Y.-Y.; Chen, M.-J.; Ren, Y.-L.; Zhou, K.-N.; Cheng, Z.-J.; Wang, J.-L.; et al. A rice virescent-yellow leaf mutant reveals new insights into the role and assembly of plastid caseinolytic protease in higher plants. Plant Physiol. 2013, 162, 1867-1880. [CrossRef]

85. Lichocka, M.; Schmelzer, E. Subcellular Localization Experiments and FRET-FLIM Measurements in Plants. Bioprotocol 2014, 4, e1018. [CrossRef]

86. Goujon, M.; McWilliam, H.; Li, W.; Valentin, F.; Squizzato, S.; Paern, J.; Lopez, R. A new bioinformatics analysis tools framework at EMBL-EBI. Nucleic Acids Res. 2010, 38, W695-W699. [CrossRef] [PubMed]

87. Tamura, K.; Peterson, D.; Peterson, N.; Stecher, G.; Nei, M.; Kumar, S. MEGA5: Molecular evolutionary genetics analysis using maximum likelihood, evolutionary distance, and maximum parsimony methods. Mol. Biol. Evol. 2011, 28, 2731-2739. [CrossRef] [PubMed] 